\title{
Preschool children's mathematical arguments in play-based activities
}

\author{
Beate Nergård ${ }^{1}$ (iD
}

Received: 12 March 2021 / Revised: 16 August 2021 / Accepted: 30 August 2021

(c) The Author(s) 2021

\begin{abstract}
The present study examines the structure and mathematical content of children's mathematical arguments as part of communication in play-based activities. It shows how Nordin and Boistrup's (The Journal of Mathematical Behavior 51:15-27, 2018) framework for identifying and reconstructing mathematical arguments, which includes Toulmin's model of argumentation, the notion of anchoring (Lithner, Educational Studies in Mathematics 67:255-276, 2008) and a multimodal approach, can be used to identify and explore preschool children's mathematical arguments. Two different types of argument that occurred during play-based activities were identified: partial arguments and full arguments. The findings reveal the extensive use of multimodal interactions in all parts of the children's mathematical arguments. Moreover, the findings point to the crucial role of adults as dialogue collaborators in the argumentation that emerges in the play-based activities.
\end{abstract}

Keywords Preschool · Mathematical arguments · Play-based activities · A multimodal approach

\section{Introduction}

Many recent studies display an interest in mathematical argumentation (Krummheuer, 2007; Mueller, 2009; Nordin \& Boistrup, 2018). Arguments, often studied in connection with argumentation and/or reasoning, are seen as a key part of mathematics and as an important basis for how the forming and understanding of opinions is developed (Schwarz et al., 2010). Argumentation has been widely explored in primary and secondary school and is acknowledged as a highly relevant learning strategy based on discursive interactions in the classroom (e.g. Mirza \& Perret-Clermont, 2009; Yackel \& Cobb, 1996).

Beate Nergård

bne@dmmh.no

1 Queen Maud University College of Early Childhood Education, Trond Nergaards veg 7,

N-7044 Trondheim, Norway 
Researchers have recently turned their attention to preschool as an environment where children develop argumentative skills (e.g. Dovigo, 2016; Pontecorvo \& Arcidiacono, 2010; Zadunaisky Ehrlich, 2011), and there is a growing body of research on preschool children's mathematical reasoning, justification and argumentation. Some studies have explored the preschool childrens' use of concrete objects, gestures and verbal language in mathematical explanations (e.g. Johansson et al., 2014; Sumpter \& Hedefalk, 2015). The findings illustrate how the relationship between verbal language, gestures and verbal objects can be viewed in regard to children's arguments and explanations. Other studies have focused on the conversational moves that teachers use to support childrens' mathematical argumentation (Björklund, 2008; Björklund et al., 2018; Lee \& Ginsburg, 2009; van Oers, 1996). The findings show that guidance from an adult is more likely to help children gain more extensive and explicitly investigated mathematical ideas and reasoning. Sumpter (2016) finds that more research is needed to explore how the teacher might promote the justifications, clarifications and evaluations of childrens' arguments. Moreover, she claims that even though the body of research on preschool children's mathematical reasoning is growing, few studies have used or anchored their analysis on theories and frameworks about mathematical reasoning. In this article I illustrate how Nordin and Boistrup's (2018) framework for identifying and reconstructing mathematical arguments can be used to identify and explore the structure and content of preschool children's mathematical arguments as part of communication in play-based activities. The following research question is addressed: What characterizes the structure and mathematical content of children's mathematical arguments in play-based activities? The arguments in the study were created during playbased activities where one or several children were actively justifying mathematical claims and conclusions to others. This article is based on a qualitative case study of a Norwegian preschool. Nordin and Boistrup's (2018) framework for identifying and reconstructing mathematical arguments is used, including Toulmin's model of argumentation, the notion of anchoring (Lithner, 2008) and a multimodal approach.

\section{Research on mathematical reasoning and argumentation in preschool}

Pontecervo and Sterponi (2002) explored preschool children's (age 4-5) reasoning when participitating in collective narrative activities. Their findings revealed that the children's reasoning unfolded "through complex argumentative patterns" (p. 133). The study shows how children use hypothetical and counterfactual devices in their reasoning, and when conflicting persepctives are opposed, the children use complex refined discursive strategies and rhetorical moves to achieve agreement and consensus. Tsamir et al. (2009) examined the types of justification provided by preschool children (age 5-6) as they worked with numerical and geometric tasks, finding that they were able to justify their conjectures by using appropriate mathematical procedures, such as counting, or by referring to critical attributes of geometric figures. Tsamir et al. (2009) call for more research on justifications young children use. The current study aims to explore children's mathematical arguments in the context of play-based activities. 
In a study of preschool children's (age 1-5) mathematical reasoning during free outdoor play, Sumpter and Hedefalk (2015) found that the children used a variety of products, such as concrete materials, their fingers and mathematical procedures in their mathematical argumentation when they challenged, supported and advanced their reasoning. Similarly, a study by Johansson et al. (2014) of children's (age 4-5) mathematical explanations in adult-initiated conversations with multimodal interactions illustrated how the relationship between verbal language, gestures and concrete objects (glass jars) could be viewed in relation to young children's explanations. According to Johansson et al. (2014), young children's use of gestures in their explanations has not been systematically researched in mathematics education. The current study aims to explore this.

Only a few studies have examined the structure of preschool children's mathematical arguments. Breive (2017) explored children's argumentation in an adultinitiated activity,using a model of argumentation by Toulmin (2003) (see Fig. 1) to investigate children's argumentation when a group of six children (age 5) worked on a symmetry task, led by a preschool teacher. The findings showed that the children were able to use several structural elements (claim, data, warrant, backing and qualifier) in their argumentation. Sumpter (2016) explored young children's (age 3-5) mathematical reasoning by using two frameworks about mathematical reasoning. The first framework, which builds on the notion of anchoring and imitative and creative reasoning (Lithner, 2008), focused on arguments and warrants and was used to analyse individual reasoning. The second, building on Toulmin's model (2003), was used to identifiy strategic choices and structural aspects of the children's reasoning that were developed in groups. In both frameworks, the mathematical foundation was important. Sumpter (2016) claims that few studies about preschool children's mathematical reasoning incorporate theories, and theoretical concepts are rarely discussed explicitly. The present study sheds light on how Nordin and Boistrup's (2018) framework for identifying and reconstructing mathematical arguments, including Toulmin's model of argumentation, and the notion of anchoring (Lithner, 2008), can be used to identify and explore children's mathematical arguments.

Fig. 1 The pared down model of argumentation (Toulmin, 2003, see also Krummheuer, 1995)

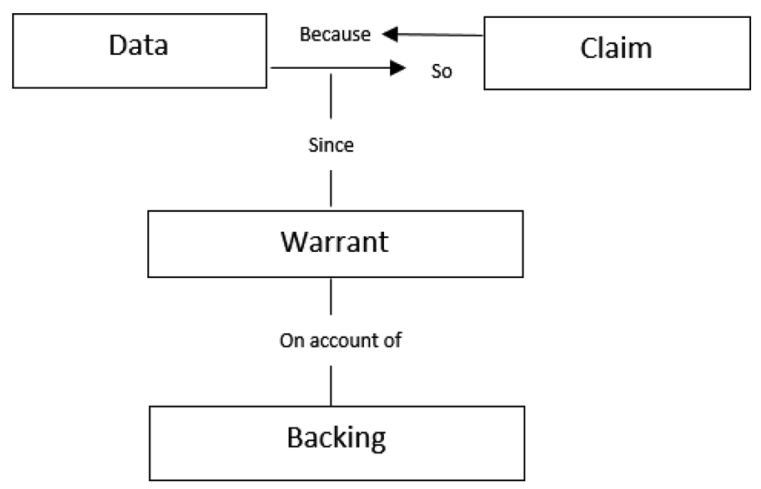




\section{Research on preschool teachers supporting children's argumentation}

With guidance from an adult, the children's mathematical ideas can be more extensively and explicitly examined (e.g. Björklund et al., 2018; Lee \& Ginsburg, 2009; van Oers, 1996). Dovigo (2016) argues that the teacher's use of conversational moves is crucial if argumentation is to arise in children-teacher talk. Krummheuer (1995) suggests that the teacher "should try to push the communication as close as possible towards point of breakdown" (p. 263) to promote the justifications, clarifications and evaluation of arguments.

Conner et al. (2014) proposed a framework for examining how teachers might support collective mathematical argumentation, including teachers' direct contributions to arguments, the kind of questions they ask and other supportive actions. They found that preschool teachers used five types of supportive actions: directing, promoting, evaluating, informing and repeating actions. Similarly, Dovigo (2016) explored the turn-taking process that enables agreements and disagreements to unfold through sequences of various conversational moves, which he characterized as open or closed questions, short answers, reparations (softens the expression of disagreement), adversatives (combine the disagreement with a contradictory opinion), repetitions and explanations. Björklund et al. (2018) explored the lines of action preschool teachers' use when teaching mathematics in play. Their study points out that open questions can promote creative reasoning whereby the children have to develop new (to them) arguments, as they do not know the formal answer to the question. The study finds that the preschool teacher's role is to follow the child's lead and guide it into the context of the environment without disturbing or controlling the play. Instead, the preschool teacher more or less extends the mathematical content within the play in various ways (Björklund et al., 2018). Sumpter (2015, 2016) calls for more research on how the teacher might facilitate children's mathematical reasoning. The present study explores the role of the teachers as dialogue collaborators in the argumentation that arises in play-based activites.

\section{Arguments and argumentation}

My study is informed by sociocultural views on argumentation as a cultural and historical activity, where interaction is characterized by the use of tools and especially by the use of language (Vygotsky, 1978). I consider argumentation to be part of preschool communication. It is a social and situated practice through which adults and children develop explanations and provide justifications to negotiate shared understanding on the same subject.

Arguments and argumentation are often studied in connection with each other (Nordin \& Boistrup, 2018), and for this reason I include research on both. Toulmin (2003) distinguishes between analytical argumentation and substantial argumentation. Analytical argumentation, referring to all logically valid 
deductions, is used in mathematical proofs. Substantial argumentation is informal argumentation used in everyday practices in which a statement is gradually supported by having a convincing presentation of backgrounds, relations, explanations and justifications (Krummheuer, 1995). Toulmin (2003) points out that substantial argumentation should not be regarded as less important or weaker than analytical argumentation.

Toulmin et al. (1979) describe an argument as a sequence of interlinked claims, and the reasons connecting them. Similarly, Stylianides (2007) describes an argument as "a connected sequence of assertions intended to verify or refute a mathematical claim" (p. 2). Conner et al. (2014) define argumentation very broadly and include "any instance where students and teachers make mathematical claims and provide evidence to support them" (p. 404). Nordin and Boistrup's (2018) description of an argument, building on the description by Toulmin (2003), views a supported claim as an argument, where it might or might not be interlinked with other arguments. I use Nordin and Boistrup's (2018) description of arguments and their framework for identifying mathematical arguments as supported claims created in preschool play-based activities. The preschool children's supported claims that we see in this article can be described as arguments conveying mathematical aspects.

\section{Toulmin's model of argumentation}

To identify the arguments in the empirical data and analyze structural and functional aspects of argumentation, many studies of students in school and some studies of preschool children map the structure of arguments using Toulmin's (2003) model (e.g. Krummheuer, 2007; Nordin \& Boistrup, 2018; Sumpter, 2016; Wagner et al., 2014). Toulmin's model provides both a language for describing argumentation and a means for structuring the components of an argument. According to Toulmin (2003), an argument involves a combination of claims, data, warrant, rebuttals, qualifiers and backing. The claim is the initial statement, for example an opinion, a conclusion or an assertion about something. If this claim is challenged, the arguer must be able to establish data, which are facts or statements on which the claim can be grounded. Warrant is a justification for the data with respect to the claim, showing the relationship between the data and claim. Warrant holds the argument together by legitimizing the inference applied from data to claim. Backing is a statement that supports warrants by providing data that substantiate and serve as evidence for the warrant. While qualifiers say something about the extent to which data confirm, the claim and rebuttals are exceptions or conditions under which the claim is held to be true.

Krummheuer (1995) introduced a pared down version of Toulmin's model for investigating collective argumentation in classroom settings (see Fig. 1). The streamlined model adopted here and used in this article contains four of the original six elements: claim, data, warrant and backing. 


\section{Mathematical arguments}

The literature is not always clear as to what makes an argument mathematical. Mueller et al. (2012) define a mathematical argument as one with the intention of convincing someone about the truth of mathematical ideas. Lithner (2008) uses the notion of anchoring arguments in relevant mathematical properties of the talk components, which are objects, transformations and concepts. Objects are fundamental entities: "the 'thing' that one is doing something with" (Lithner, 2008 p. 261), a transformation is the process the object undergoes, while concepts are key mathematical ideas based on the objects, transformations and their properties (Lithner, 2008). In a similar vein, Sumpter (2016) claims that if mathematical objects, transformations and concepts are present, the warrant and backing of an argument can be analysed from the point of view of mathematical content. Similarly to Nordin and Boistrup (2018), I draw on Lithner's (2008) notion of anchoring for the identification of arguments as being or not being mathematical in nature.

\section{Gestures and concrete objects}

In addition to spoken and written language, mathematical arguments and argumentation may be investigated through a variety of modes, such as pointing, gesturing and drawing (e.g. Conner et al., 2014; Nordin \& Boistrup, 2018). Radford's (2002, 2003 ) theory of knowledge objectification points out how the combination of gestures, bodily actions, artefacts, (mathematical) signs and speech affect mathematical reasoning and argumentation. "Pointing at something in the visual field of the speakers" (Radford, 2002 p. 17) plays a significant role in the mediation of mathematical arguments. Children's different ways of expressing their arguments and reasoning, either through spoken words and gestures or by just pointing at something, are seen as an important part of their argumentative talk (Radford, 2009). McNeill (2008) also considers gestures as a powerful tool for promoting collective and individual arguments and reasoning. Moreover, concrete objects are considered to be an essential part of children's argumentation. Sfard (2008) claims that the concrete objects used in the context of children's mathematical ideas can contribute to their argumentation and make the communication more explicit. Nordin and Boistrup (2018) argue that several modes often interact with each other when interlocutors express their claims, data and warrants. In their framework, Nordin and Boistrup (2018) show how the use of a multimodal approach makes it possible to identify arguments created during interaction as a meaning making process. Inspired by Nordin and Boistrup (2018), and research that highlights the importance of children's multimodal communication (Johansson et al., 2014; Sumpter \& Hedefalk, 2015), this article takes a multimodal approach to ensure that the identification and analysis of informal arguments are not excluded as part of interaction in play-based activities. By adopting a multimodal approach, I understand arguments and argumentation as more than spoken language, bringing a broader range of modes, such as moving concrete objects and using gestures, into focus. 


\section{Participants and the setting}

A privately operated preschool in Norway served as the setting for this study, and the data material in this article is a part of a lager data set collected for my $\mathrm{PhD}$. This is a special preschool because it focuses on natural science, and 5-year-olds from four different preschools visit here 1 week at a time every 5 weeks. Over the period of 1 year, I studied the children from one of the four preschools when they were present in this special preschool over a period of 7 weeks. The participants in this study were 25 five-year-old children and adult staff; three preschool teachers and two teaching assistants. The three preschool teachers had 6 to 12 years of experience after graduating, while the two teaching assistants had been working in a preschool for 5 and 7 years, respectively.

Here, I am interested in children's argumentation as part of communication in play-based activities. Play is at the core of early childhood education (Singer, 2013), and has an important role in the Norwegian preschool curriculum. The OECD (2006) has described the Norwegian preschool context as reflecting the socio-cultural tradition where core focus points are upbringing, care, play and learning. Although it is situated in a social pedagogy tradition, mathematics is increasingly regarded as an important domain where the task of preschool teachers is to nurture the children's development of mathematical thinking. In the Norwegian preschool context, mathematics is normally taught through everyday activities, adult-initiated activities and play situations. In the preschool studied here, play-based activities consisted of a play environment that was structured by adults, but where the children had control over how and what they wanted to play (Walsh et al., 2006). The adults interacted with the children as needed and participated in the children's exploration without disturbing the play. Such a play environment was facilitated, three hours every day, by the adults so the children had the opportunity to explore mathematics within play. In this study I examine argumentation that occurs in the context of play-based activities.

\section{Methods and analysis}

The aim of this study is to explore the structure and mathematical content of children's mathematical arguments as part of the communication in play-based activities in one preschool. The arguments in the study were created during playbased activities where one or several children were actively justifying mathematical claims and conclusions for others. The study can be characterized as a qualitative case study, meaning it is bound by time and place (Creswell \& Poth, 2016), as I studied a preschool for a period of 7 weeks spread over 1 year with the aim of focusing on mathematical communication and language.

The research relies on authentic documentation from the preschool where children and teachers are engaged in different play-based activities and with different content. The data material comprises 15 video recordings of play-based activities 
initiated by the children. The length of the video recordings varies from three to approximately $21 \mathrm{~min}$. A Q4 Handy Video Recorder was used to record the play-based activities. It was held close to the activities and the participants so that use of the play material and the participants' body language could be read clearly. Nvivo data analysis software was used to analyse the video recordings. It was impossible to have direct access to the participants' thinking. However, the video recordings of the activities enabled me to observe and transcribe their verbal exchanges and gestures, and how they handled the play material.

I applied Nordin and Boistrup's (2018) analytical framework to identify and reconstruct mathematical arguments. In this framework, the reduced version of Toulmin's model (2003) was used to identify the elements of an argument. First, I identified claims, such as an opinion, a conclusion or an assertion about something. Then I searched for any data supporting each claim. If data supporting a claim were identified, I searched for warrants and backing. As in the framework by Nordin and Boistrup (2018), I drew on the concept of anchoring (Lithner, 2008) to clarify whether or not the argument could be seen as mathematical. In accordance with Nordin and Boistrup (2018, p.11), I identified the arguments step-by-step:

(1) identified claims in the video recordings,

(2) searched for data which supported the claim,

(3) searched for warrants which motivated how the data supported the claim,

(4) I also made sure that the argument was anchored mathematically,

(5) searched for possible warrants which motivated the warrant, and

(6) interpreted the identified elements, taking the particular context into account, when writing the reconstructed argument as a supported claim.

Moreover, I used a multimodal approach to identify the mathematical arguments through a broad range of modes, such as speech, gestures (pointing) and moving an artefact. The preschool teachers also took part in the communication during playbased activities, and to highlight the structure in the children's arguments, I used the studies by Conner et al. (2014) and Dovigo (2016) when I analysed the adult's use of conversation moves in the communication, characterizing the teachers' conversational moves, for instance, as open or closed questions, short answers, elaboration or asking for explanations. Examples selected from the data material were chosen because they were representative of the findings, involving a number of children and the three preschool teachers and two assistants.

\section{Ethical considerations}

Björklund (2010) points out that video observations are an appropriate method for observing situations where adults and children are in dialogue with each other. However, video observation as a method requires critical reflection especially when it comes to the relationship between children's competence and vulnerability. As a researcher, I had a responsibility for the children's participation even though the 
parents had consented to their child's participation. I always had to observe if the children's verbal and nonverbal expressions said something about their desire to be a part of the observations. This project was approved by the Norwegian Social Science Services (NSD) and satisfied their privacy requirements. Informed consent to the filming of activities was given by the children's parents and the five adults. The video observations were made while showing respect and sensitivity towards the participants, and the camera was switched off when the participants' expressions indicated reluctance or discomfort (Løkken, 2012). No list of participants was established, and all the data material will be deleted when the project is concluded.

\section{Findings}

In the analysis of the 15 video recordings, thirty-seven dialogue sequences where claims were uttered by a child were identified. During the analysis, I identified some concrete and isolated claims by the children and a brief response by the adult that did not lead to further arguments or dialogue. On the other hand, approximately a fourth of the sequences were long cohesive dialogues consisting of more than one utterance by the child and the adult. The identification of these different types of conversation resulted in two main categories, which I called: partial arguments and full arguments.

I will describe the partial arguments first. In each example, the play environment was structured by the adults. Some of the play material was the same, while some differed from time to time. The children had control over how and what they wanted to play. The adults offered extensions without distroying, disrupting or controlling the play.

\section{Partial arguments}

The partial argument starts with a claim (C) that the child makes. The child's claim (C) refers to what is taking place in the play or is focused on something that is not

Fig. 2 Reconstructed picture of a similar train to the one the boy is playing with

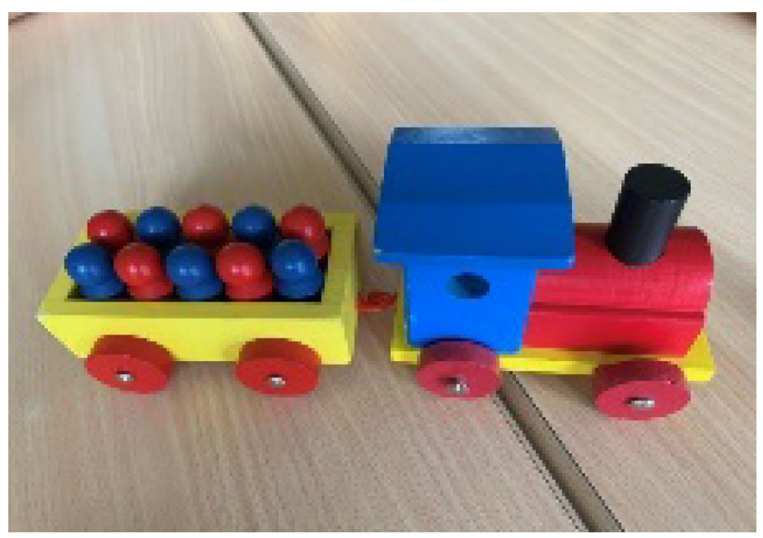


right. The claim is followed by a brief comment or no response from the adult, and then the verbal dialogue stops. In all of the partial arguments the children convey the data (D) supporting their claims by physically handling the concrete objects they are playing with. Two representative examples are be presented here to illustrate this.

In the first example, a boy ( 5 years old) is playing with a train and five carriages (see Fig. 2). The adult sits next to the boy and observes the activity.

The boy is putting passengers into the carriages, and each carriage is only capable of holding ten passengers. He drives the train over the floor between the stations where he has already placed various numbers of passengers. When he has filled three of the carriages with a total of thirty passengers, he makes a claim.

\begin{tabular}{lll}
\hline Who & Speech & Actions \\
\hline Boy: & Now there are ten in here & $\begin{array}{l}\text { Points to the last carriage he has } \\
\text { filled with passengers }\end{array}$
\end{tabular}

Boy:

The boy continues to drive the train between the stations he has made on the floor and fills up with passengers in the last two empty carriages. After approximately $30 \mathrm{~s}$, the boy stops the train at a station and counts the passengers

Boy: $\quad$ But something's not right here

Now the first four carriages are filled up with ten passengers and the last carriage holds nine Boy:

Points to the passengers in the last carriage, one by one and quietly counts the passengers. Then he places another passenger in the last carriage, so it holds ten, and the boy counts the passengers again

Adult:

Watches when the boy counts and does not give any verbal response to the boy's claim

The boy claims that the last carriage he filled has ten passengers (C), a mathematical claim that establishes the number of passengers in the carriage. The adult responds by repeating the boy's claim about the number of passengers in the carriage $(\mathrm{R})$. The boy continues playing and later in the same activity makes a new claim about the number of passengers in the last carriage he filled: "But something's not right here" (C). The adult looks at the boy and gives no verbal response (R). The boy checks his claim by counting the passengers. The counting of the objects is identified as anchoring (Lithner, 2008) the argument mathematically. When counting, the boy assigns one and only one number word to each object (Gallistel \& Gelman, 1992). The fact that the boy adds another passenger to the carriage may be interpreted as his 
Fig. 3 Reconstructed illustration of the boy's figure

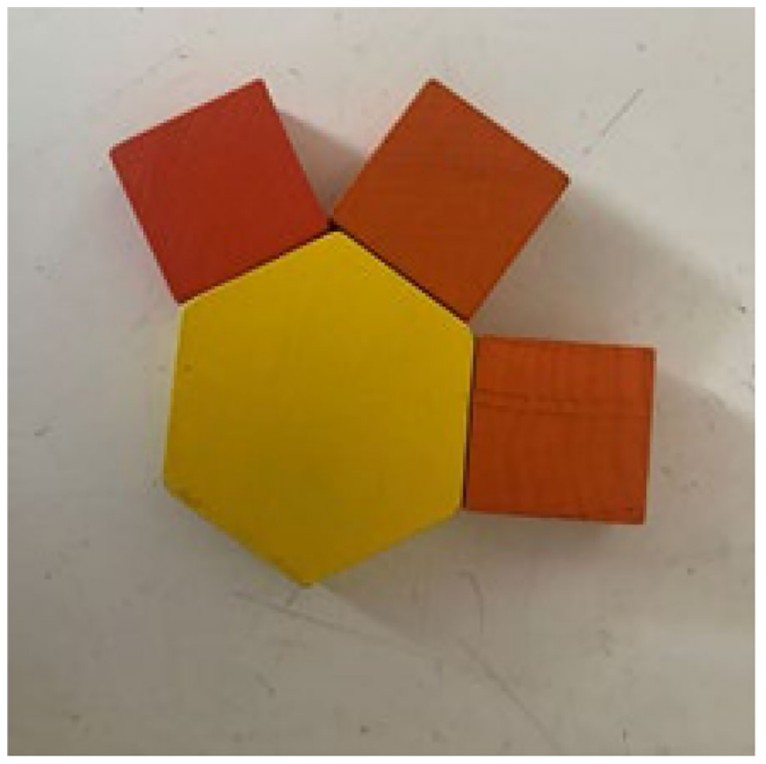

data (D) supporting his claim that something is not right and that he needs another passenger to have the correct number of passengers in the carriage. In this case, the quiet counting and the moving of the objects to add the final passenger are the modes which convey the meaning of his data (see Fig. 4). As I will come back to in the discussion, it is worth making note of the different modes in research on preschool communication (Nordin \& Boistrup, 2018). In the next example, a boy (5 years old) is sitting at a table building various figures using geometrically shaped building blocks, and the adult sits next to him watching the activity. The boy has made a figure consisting of a hexagon in the middle and squares on three of the sides of the hexagon (see Fig. 3).

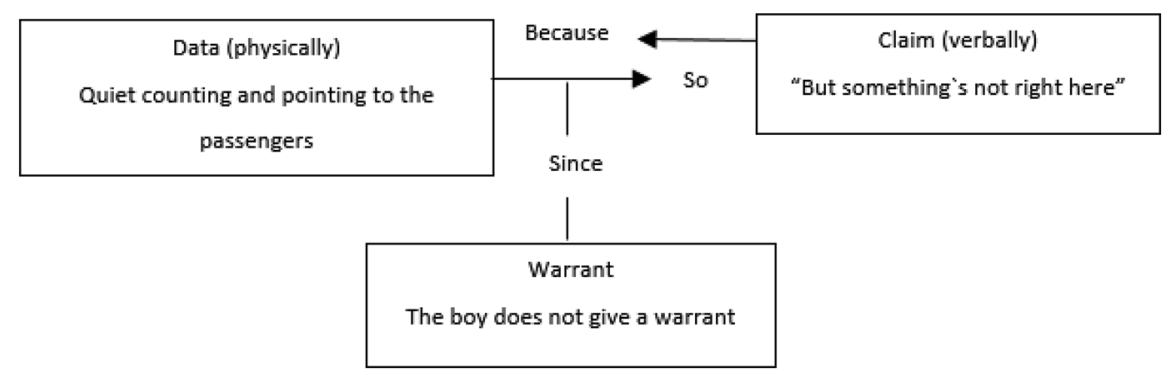

Fig. 4 Reconstructed arguments for the first partial arguments 


\begin{tabular}{|c|c|c|}
\hline Who & Speech & Actions \\
\hline Boy: & I need more of these squares & Points to a square \\
\hline Adult: & Do you? & \\
\hline Boy: & & $\begin{array}{l}\text { The boy continues to look for squares, finding three } \\
\text { more, and puts them on the three final sides of the } \\
\text { hexagon }\end{array}$ \\
\hline Boy: & Now it's the same on all the sides & Placing the last square along the sides of the hexagon \\
\hline Adult: & It's nice & \\
\hline
\end{tabular}

The boy first makes a claim that he needs figures shaped like a square so he can build his figure and finish it (C). The adult responds with a closed question (R). The boy looks for squares and finds three squares that he places along the sides of the hexagon. The fact that he searches for and selects squares and finishes his figure may be interpreted as his way of explaining the data (D) and supporting his claim that he needs more squares. Thus, he conveys the data by moving the figures. The use of the mathematical concept square and the transformation of the squares (objects) by putting them up against the three final sides of the hexagon are identified as anchoring the argument mathematically (Lithner, 2008). He then makes a new claim that now all the sides are the same $(\mathrm{C})$. The adult responds with a brief comment that the figure is nice (R). "Now it's the same on all the sides" may also be interpreted as data (D) supporting his initial claim, but that is somewhat uncertain because the boy was not challenged to give a verbal explanation as to why he needed the squares and how he could claim that "Now it's the same on all the sides".

To summarize, the boys spoke very little, and started moving the objects in order to display their solutions to the problems. Moving the objects was the mode that conveyed the meaning of their data. By using a multimodal approach, I consider the children's non-verbal arguments as a part of their argumentation (Nordin \& Boistrup, 2018). These objects in the play, the passengers and the squares, and what the boys physically do with them, are interpreted as constituting the data (D) for their claims (C). However, since the boys do not give warrants (W), the relationship between the claim (C) and the data (D) is less clear. When the children are not challenged by the adult's response (R) to give grounds for their claims, the various elements in their arguments become less obvious, and the rationale that shows the link between the claim and the data is missing. This finding is not surprising as other studies (e.g. Björklund et al., 2018; Krummheuer, 1995) have pointed out the need for teachers to extend the children's mathematical ideas and push the communication to promote the justification of arguments.

The analyses indicate that the structural aspects of the argumentation that arise in the partial arguments comprise a claim (C) by the children, a response (R) from the adults and then finally the children convey the data (D) through physically handling the concrete objects they are playing with (see Fig. 4).

\section{Full arguments}

In the full arguments, the dialogue between the child and the adults contributes to the child arguing for his or her claim. Here the child starts with a claim (C) and the 
Fig. 5 Reconstructed illustration of the train and where the boy points

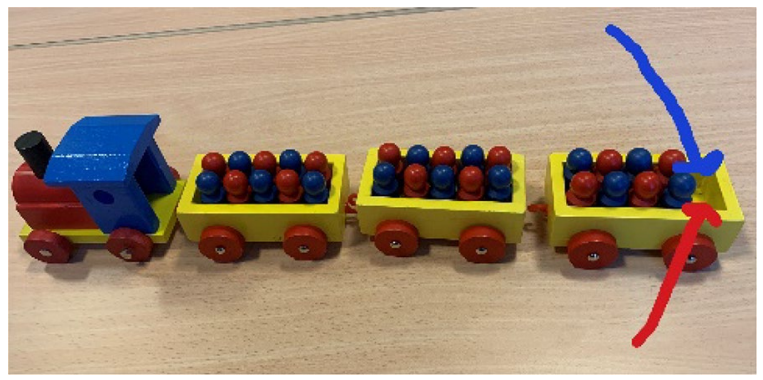

adult responds by asking for explanations, repetitions and/or more information about the child's claim through questions (R), after which the child presents data (D) for his or her claim by using the concrete objects and then explanations, or warrants (W). I will present four examples which show what the structure and mathematical content are in the children's full arguments. The first example below, where the mathematical content is patterns (Tsamir et al., 2017), illustrates the structure of a boy's arguments when the adult responds with an open question about his claim. A boy ( 5 years old) and an adult are sitting on the floor playing with trains and train carriages. Each carriage holds ten passengers, and the passengers come in two colours, blue and red (see Fig. 5). The boy has filled two carriages so that the passengers in the carriage are standing in an alternating blue and red pattern.

\begin{tabular}{|c|c|c|}
\hline Who & Speech & Actions \\
\hline Boy: & & Fills the third carriage with eight passengers \\
\hline Boy: & Now I want a red one there & $\begin{array}{l}\text { Points to a vacant space in the last carriage (red } \\
\text { arrow in Fig. 5) and places a red passenger } \\
\text { where he has pointed }\end{array}$ \\
\hline Adult: & $\begin{array}{l}\text { So you want to have a red passenger? } \\
\text { Why do you want to do that? }\end{array}$ & \\
\hline Boy: & $\begin{array}{l}\text { Because I want a red one there } \ldots \text { a red one } \\
\text { there } \ldots \text { a red one there... a red one there... } \\
\text { and a red one there }\end{array}$ & $\begin{array}{l}\text { Points at the red passengers, one by one, in the } \\
\text { third carriage }\end{array}$ \\
\hline Boy: & Like that & Looks at the adult and points to the carriage \\
\hline Boy: & And there I want a blue one & $\begin{array}{l}\text { Points to the last empty place in the carriage } \\
\text { (blue arrow in Fig. 5) }\end{array}$ \\
\hline
\end{tabular}

The boy makes a statement that he wants to place a red passenger in the carriage (C), and the claim is mathematically anchored to the colour pattern of the passengers. The adult responds with an open question asking why he wants a red passenger (R). To argue for his claim, the boy places the passengers in a repeating ABAB colour pattern (Tsamir et al., 2017). The placement of the passengers, alternating red and blue, constitutes his data (D) supporting his claim. He also gives a verbal description of the repeating pattern by indicating how the red passengers are placed in the pattern. By using the conjunction "because" while pointing at the red passengers and naming the colour "red", he provides data (D) 
for his claim about where the red passenger must be placed in the pattern. He also elaborates on his grounds by making it clear that the final passenger must be blue for the pattern to be right. This clarification and the mathematical warrant (W) relate the data, how the pattern is constructed according to a colour scheme, to the claim "Now I want a red one there" (see Fig. 6). The boy's argumentation is closely connected to the concrete objects he is playing with. His claim in this activity is related to the colour of the passengers and how they have been placed in the pattern. In his mathematical warrant relating to how he wants the pattern to be, he places and points to the passengers while giving a verbal explanation of the pattern. The moving of objects, speech and hand gestures (pointing) conveyed the boy's argument. The transformation of the passengers (objects) by placing them in a linear repeating ABAB pattern (Tsamir et al., 2017) is identified as anchoring (Lithner, 2008) the argument mathematically.

The example illustrates how the three elements of claim, data and warrant have been part of the child's mathematical argumentation. First, the boy states a claim (C). The adult responds with an open question (R) about the claim and the boy presents data (D) for the claim and a mathematical warrant (W), which relates the data to his claim. The boy argues further and refers to the connection between claim and data by elaborating on his warrant (W) by pointing out more accurately how the pattern is structured. This example also illustrates how the adult's open questioning response contributes to the boy offering a mathematical warrant for his claim.

As the example above illustrates, a prominent characteristic in children's mathematical arguments, using data and warrant for their claims, is what they physically do when they use concrete objects, such as moving, building and counting. In the full arguments, the adult's use of questions, or asking the child to explain or elaborate on their statements, encourage the child to argue further for their claim by giving a supportive explanation (W) using speech and gestures. The example below, which is a play-based activity where a girl (5 years old) and an adult are sitting together at a table and building various figures with geometrically shaped figures, also illustrates this.

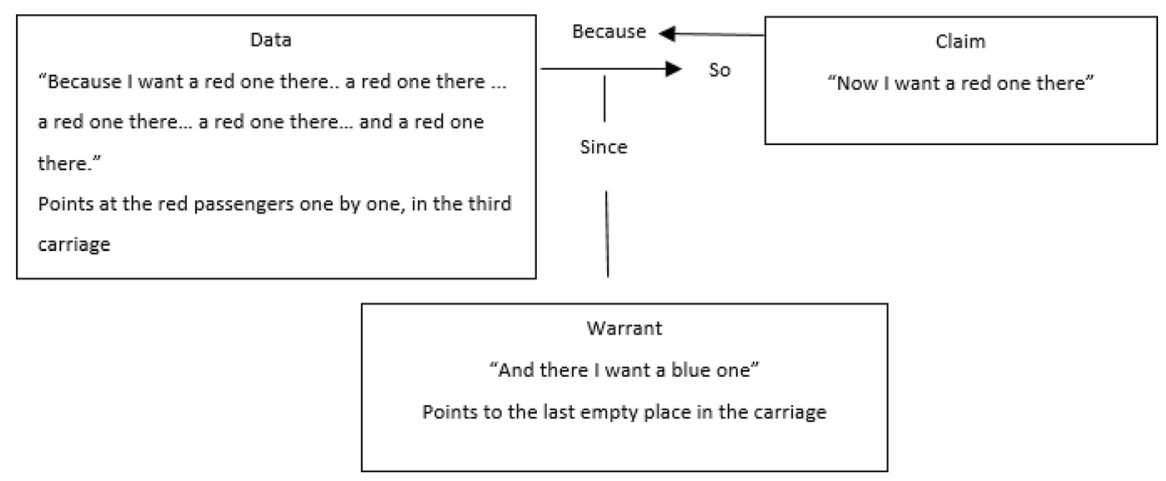

Fig. 6 Reconstructed arguments for the pattern 


\begin{tabular}{lll}
\hline Who & Speech & Actions \\
\hline Girl: & $\begin{array}{c}\text { Now I'm going to make a house. It's really } \\
\text { easy to make a house }\end{array}$ & \\
Adult: & $\begin{array}{l}\text { Is it easy to make a house? } \\
\text { Could you make one for me then? }\end{array}$ & Puts together a triangle and a square \\
Girl: & & Puts a triangle next to a square, points to what \\
Adult: & What did you do now? & she has made and looks at the adult \\
Girl: & $\begin{array}{l}\text { It's like this, see. So easy. Two pieces, put } \\
\text { them together }\end{array}$ & \\
Adult: & How did you make it into a house? & Joins a square and triangle with two new pieces \\
Girl: & Just took one of these, a square and a triangle &
\end{tabular}

The girl claims that it is easy to make a house (C). The adult responds with a question, asking her to make her a house (R). To argue for her claim, the girl builds a house using a triangle and a square. The figures, the square and the triangle, and what the girl does with the figures, constitute the data supporting her claim (D). She gives no explanation about the data, and the adult asks her to explain and elaborate on what she is doing with the figures (R). The girl describes what she does when she builds a house, describing the number of concrete objects she uses, "Two pieces, put them together", while pointing out that it is "so easy". The action she takes, using two different shapes (triangle and square) and putting them together, illustrating that the combined figure has a shape like a house, justifies the step from data to conclusion. This action can be understood as appropriate in an argument for this specific claim. The adult then encourages her to explain how she made the figures into a house (R), and thus prompts her to undertake a mathematical exploration. The girl now includes mathematical words, square and triangle, in her explanation, while also building a new house using a triangle and a square. Her use of mathematical terms in her warrant (W) connects to her claim (C) and her data (D), and shows the cohesion in her arguments. She argues that it is easy to make a house using various triangles and squares. Speech and the moving of the objects are the modes that convey the meaning of her argument. The

Fig. 7 A still photograph taken from the video of the girl's working with a pattern

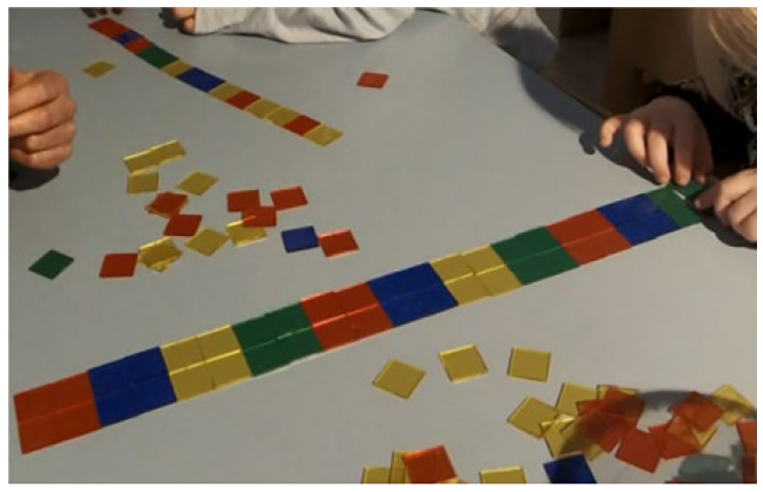


argument is anchored mathematically (Lithner, 2008) since mathematical objects (the different shapes) and concepts (triangle and square) have been addressed in the data and warrant.

As the examples illustrate, a broad range of modes, such as speech, pointing, touching and moving concrete objects are important elements in children's mathematical arguments that arise in their play-based activities. These modes also illustrate how the question and supporting actions in the adult's promoting response contribute to the child's justification and elaboration of her claims (Krummheuer, 1995), and contribute to the use of mathematical terms in the arguments.

The next example illustrates the complexity in the children's arguments when they are also able to draw on backing (B) in their explanation to strengthen their mathematical arguments. Two girls (5 years old) and an adult are sitting at a table, each making their own pattern using transparent blocks (Fig. 7).

\begin{tabular}{lll}
\hline Who & Speech & Actions \\
\hline Girl 1: & $\begin{array}{l}\text { Now I made a mistake, because I don't want it } \\
\text { to be like that }\end{array}$ & Takes a green block away from the pattern \\
Adult: & Was it wrong? \\
& What was wrong about it? & \\
Girl 1: & Because, look here! & Points to the blocks in her pattern \\
Girl 1: & Red, blue, yellow, green, red, blue, yellow, & green, red, blue... \\
Girl 1: & So that's why I can't have green now & Picks up the green block she initially took away
\end{tabular}

The girl's claim is that she has done something wrong in the repeating pattern she has made (C). She presents data (D) supporting her claim when she physically removes the block she believes is wrong. The adult's response is a question, asking her to explain why it was incorrect (R); a response from the adult centred on the correctness of the mathematics. The girl uses the conjunction "because" while she asks the adult to look at the pattern and then points at the blocks. She provides data (D) for her claim where the conjunction "because" and the pointing together constitute the data she presents. Then she presents a mathematical warrant $(\mathrm{W})$ for the data by pointing to the blocks one by one, describing the pattern: "Red, blue, yellow, green, red, blue, yellow, green, red, blue..." This verbal utterance may be seen as the girl's warrant (W), which contributes to making the argumentation more cohesive, also showing the link between the claim (C) and the data (D). The last utterance, "So that's why I can't have green now" (B), supports her argumentation (see Fig. 8). The words "that's why" are added explicitly to reinforce and refer to the claim that started the argumentation. When highlighting her argument about the wrong colour, the girl holds out the green block she removed, adding data for backing up and supporting her argument and using the objects to show how her argument is cohesive. Throughout the entire dialogue the blocks are part of her mathematical argument when she touches, moves and points to them. Thus, speech, hand gestures (pointing) and moving the blocks have been the modes conveying the meaning of her argument. The argument has 


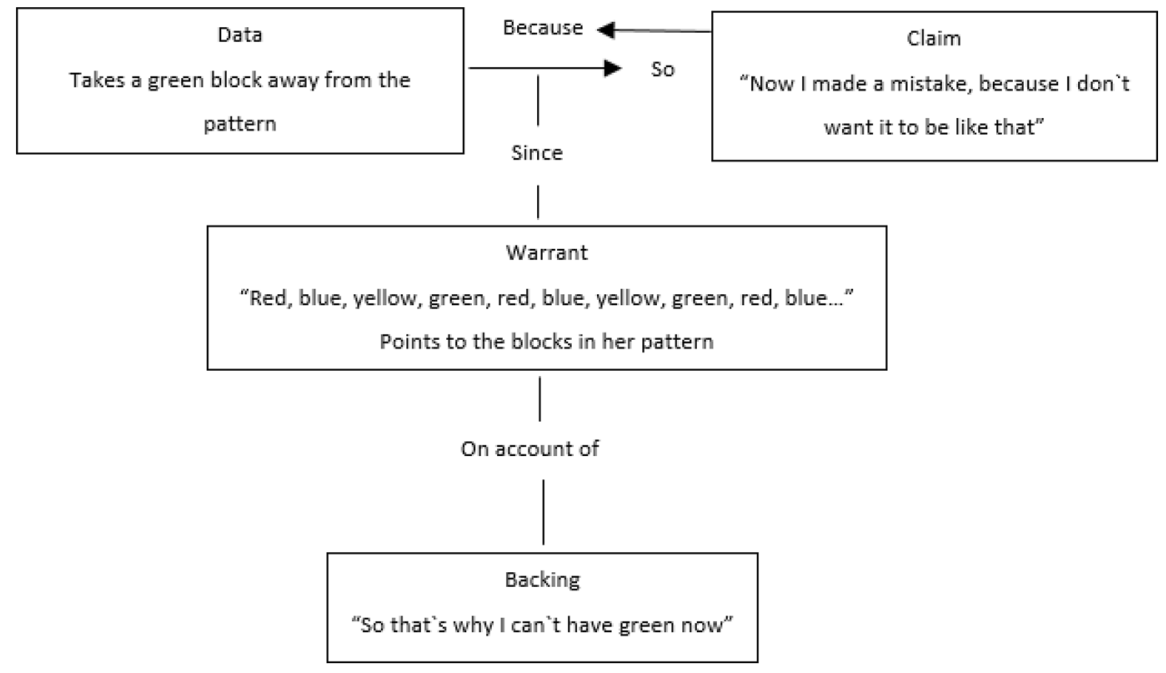

Fig. 8 Reconstructed arguments for the linear repeating pattern

been anchored mathematically since the linear repeating ABCDABCD pattern (Tsamir et al., 2017) has been addressed in the warrant and the backing.

The final example illustrates that the adult's response in the form of a question or an elaboration on the child's statements encourages the child to elaborate on her mathematical arguments by presenting mathematical backing (B) that is more precise and includes more mathematical terms. A girl (5 years old) and an adult are sitting at a table playing with geometrical blocks. The girl is making a snow crystal consisting of rhombuses (see Fig. 9).

Fig. 9 Reconstructed illustration of the girl's figure

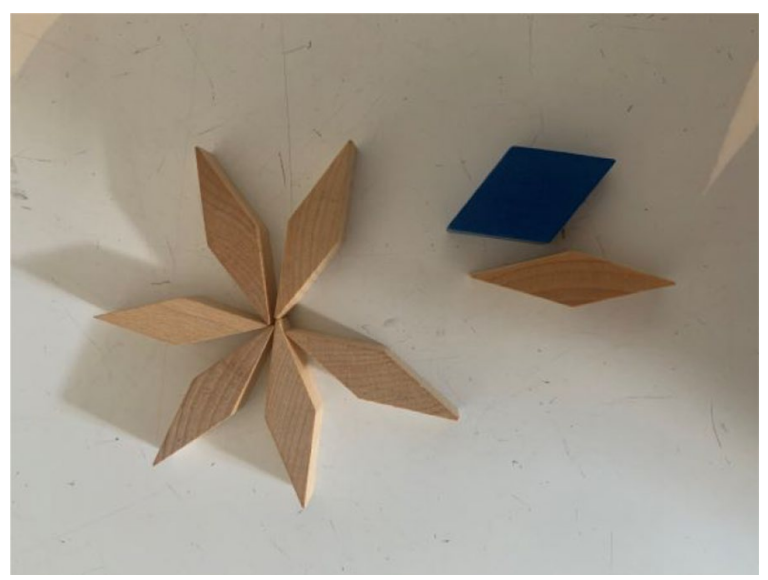




\begin{tabular}{|c|c|c|}
\hline Who & Speech & Actions \\
\hline Girl: & & Picks up a rhombus (the blue figure in Fig. 8) \\
\hline Girl: & No, it doesn't work with this one & Puts the blue block in her snow crystal \\
\hline Adult: & Why not? & \\
\hline Girl: & Because I need the small ones & \\
\hline Adult: & Can't you use any of these? & Points to the various rhombuses on the table \\
\hline Girl: & $\begin{array}{l}\text { No, I have to use the ones that are the } \\
\text { same as these on the edges }\end{array}$ & $\begin{array}{l}\text { Picks up one of the rhombuses that she has in her } \\
\text { snow crystal, moving her finger along one side of } \\
\text { the block }\end{array}$ \\
\hline
\end{tabular}

The girl makes a claim (C) that it is impossible to use the blue block she has chosen. The girl's placement of the block that she claims does not fit and the figure she has started to make constitute the data (D) which support her claim (C). The adult responds with an open question (R), "Why not?" The girl gives a mathematical warrant (W) for why it does not fit. When she explains that she needs blocks that are "small", she supports her warrant by adding a mathematical concept which elaborates her claim that the block she chose first does not work because of its size. The girl also uses the conjunction "because" in her explanation and strengthens her data and warrant for the claim. The adult comments on the girl's reasoning by proposing other solutions (R). When the adult draws the girl's attention to the other blocks, verbally and by pointing to them, she contributes to encouraging the girl to elaborate on and describe what it is about the size that does not fit. "No, I have to use the ones that are the same as these on the edges" is the girl's backing (B) for her warrant (W) supporting her data (D) and claim (C) (see Fig. 10). In her reasoning, she expands her explanation by referring to different mathematical properties of the blocks that

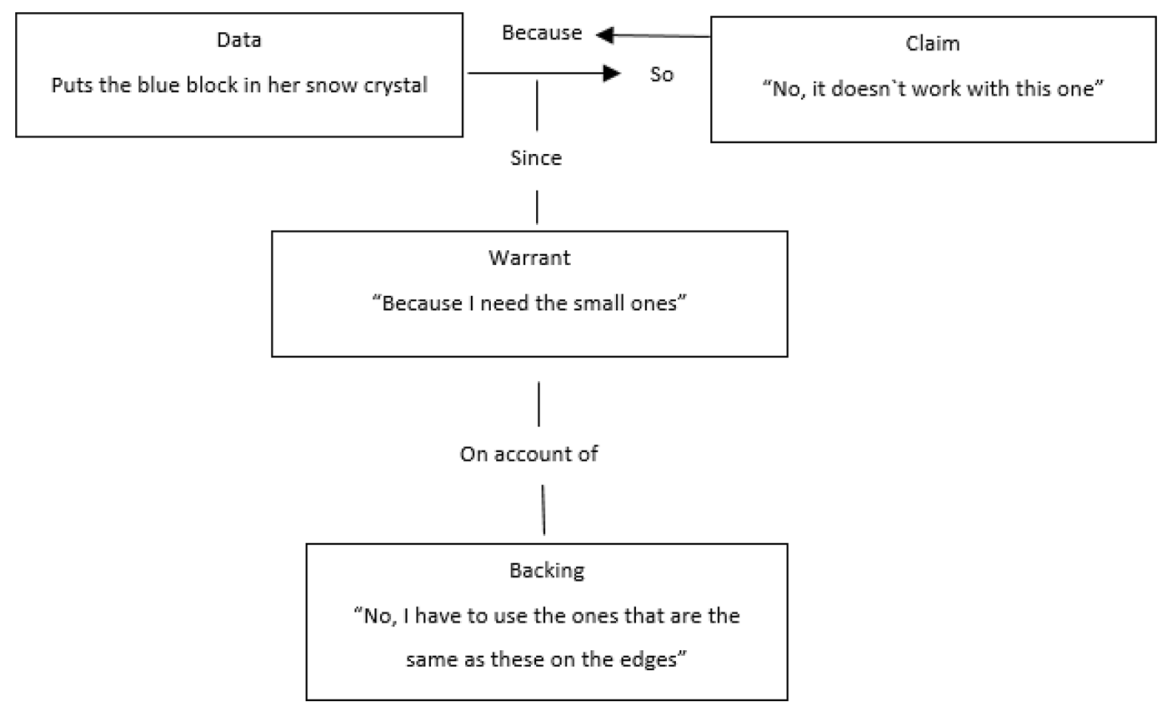

Fig. 10 Reconstructed arguments for the properties of the rhombuses 
are important, and describing the shape of the block she needs in a different way. To emphasize which rhombus she needs, the girl refers to the attributes of the shapes, the edges. She is able to justify her claim by using appropriate mathematical procedures, such as referring to critical attributes of geometric figures (Tsamir et al., 2009). In the mathematical backing (B) for which rhombus she needs, she moves her finger along the side of the block while giving a verbal explanation of its attributes. The hand gesture (finger touching the edge) and speech convey the girl's argument. The fact that she refers to the attributes of the rhombuses in her backing (B) of the argument and physically demonstrates which attribute is different can be interpreted as further reinforcement of her argumentation about which blocks fit, as well as a way of making the argumentation more mathematically explanatory. The argument is anchored mathematically (Lithner, 2008) because mathematical properties (the difference in the rhombuses' attributes) and concepts (edges) are referred to in her backing.

\section{Discussion}

In this article I have explored the structure and mathematical content of the children's mathematical arguments as part of the communication in play-based activities in a Norwegian preschool. The findings show that the children's mathematical claims and arguments arose spontaneously when they expressed an opinion about what was taking place in their play. For example, when the children found the pattern they were making was incorrect, or the shapes in the figures did not fit, they spontaneously voiced their observations in the form of a mathematical claim. Their spontaneous claims were related to something they were interested in while they were playing (Perry \& Dockett, 1998) and were connected to what occurred "here and now" during the play.

As in other studies of structural aspects of preschool children's arguments (Breive, 2017; Sumpter, 2016), the findings show that several of the elements in Toulmin's model were used in their arguments. I identified two types of mathematical arguments as part of the communication in play-based activities: partial arguments and full arguments. The partial arguments consisted of a claim by the children, a response from the adults and then the children conveyed the data by physical handling the concrete objects they were playing with. The warrant, which shows the relation between claim and data, was lacking in these arguments. In full arguments, on the other hand, the three structural elements claim, data and warrant were part of the children's mathematical argumentation. First, they stated a claim. The adults then responded to the claim and the children presented data for it and a mathematical warrant that related the data to the claim. Sometimes, the children provided backing for their argumentation, thus reinforcing it by supporting the warrant.

In both types of argument the intention of the children's claim was to establish a conclusion relating to the mathematical aspects of the concrete objects being played with or to point out what the child believed was initially incorrect and needed to be changed as it had not turned out as intended. As in other studies (Conner et al., 2014; Dovigo, 2016), the findings show that the adult's response to the child's claim 
had an impact on whether or not the argumentation was maintained or carried forward. The analyses of the partial arguments show that neither closed questions nor brief comments, such as "Yes, you did that" and "it fit", supported the children's argumentation. I found that in the situations where the adult did not contribute any supportive actions (Conner et al., 2014), the children continued to play with their concrete objects and their manipulation of the objects was interpreted as the children's data for supporting their claim (Nordin \& Boistrup, 2018; Radford, 2009). Thus, the act of moving the concrete objects was the mode that conveyed the children's data. However, the non-verbal actions of the children, in partial arguments, could also be seen as a warrant. Such a finding is less clear because the children gave no verbal grounds for their manipulation of the objects.

Sumpter (2016) argues that more research is needed to explore what can stimulate children to expand and continue their argumentation. The analyses of the full arguments show that when the adults used other conversation moves, if, for example, they asked open questions, commented on the child's claim or data, asked closed questions but at the same time proposed other solutions, or changed or expanded on what the child said, the child provided a warrant and backing to support their claim. The children used speech, moved objects and made hand gestures (pointing) to convey the data, warrant and backing (McNeill, 2008; Radford, 2009). The findings show that when the adults challenged the children to explain themselves more in depth, the mathematical arguments were encouraged, and the children used additional mathematical concepts in their warrants and backing. The adults also used other supportive actions, such as directing, promoting and evaluating. The findings show how the adults asked open questions, challenged the children to expand their explanations, and the adults suggested other solutions to challenge the children's claims. Thus, the adults served as dialogue collaborators in the argumentation that emerges in the play-based activities. Other studies (e.g. Björklund et al., 2018; Lee \& Ginsburg, 2009) indicate that when adults guide the children, they can explain their mathematical conclusions more explicitly. In the full-argument sequences in this study, the adults' supporting actions strengthened the children's arguments (Conner et al., 2014). When the children provided a warrant supporting their claim and data, they supported their ideas and gave grounds for their thoughts. The children used such pointers as "like", "because", "it's like this" and "look here". When continuing these explanations the children would often support their warrant and backing by pointing to or using the concrete objects physically while making verbal statements.

As in other studies of preschool children's mathematical argumentation and reasoning (Breive, 2017; Johansson et al., 2014; Sumpter \& Hedefalk, 2015), the findings point out that many modes, such as speech, pointing and moving concrete objects, were important elements in the children's mathematical arguments (Conner et al., 2014; Radford, 2009). The findings illustrate the children's comprehensive use of the concrete objects they played with and the importance of their physical handling of these play materials when they provided data, explained and gave grounds for their arguments. In all the elements of the argumentative structures that arose, the children pointed to, touched or moved the concrete objects to convey what they meant. This underlines the relevance of taking broad modes into account when exploring the 
children's arguments (Nordin \& Boistrup, 2018). Without the multimodal approach, some of the children's arguments, together with the contributions of the adults, could have easily been overlooked in the analyses.

The study shows that the children's arguments were related to such mathematical qualities as shape, size and pattern. Their argumentations were anchored mathematically, and thus can be seen as mathematical arguments (Lithner, 2008). The study indicates that play-based activities are a social context within which children can encounter mathematical problems where they can solve, discuss and spontaneously argue with an adult (van Oers, 2010), making play-based activities an ideal context within which children can develop their ability to argue for their ideas (Mercier, 2011).

\section{Conclusion}

According to Sumpter (2016), few studies on preschool children's mathematical argumentation and reasoning have used or anchored their analysis on theories and frameworks relating to mathematical reasoning. The current study draws on a framework for identifying and reconstructing mathematical arguments developed by Nordin and Boistrup (2018) and points out how this framework can be used to identify and explore the preschool children's mathematical arguments.

Being able to articulate reasoning and mathematical argumentation is a critical skill for young children to develop. These findings demonstrate what takes place in a preschool and whether or not the children are given opportunities to engage in argumentation with the adults. They also provide some effective examples of ways adults can help children communicate their mathematical arguments. This article has shown how play-based activities in preschool can provide opportunities for developing the children's ability to argue, and it has revealed that children's argumentation is quite complex. The mathematical argumentation that emerged from the children's spontaneous claims was largely related to what they were playing with, and the argumentation was maintained by using concrete objects in their explanations and reasons. It was found that the children use a broad range of modes to support their arguments. This study shows that children's argumentation is characterized by multimodal interaction, i.e. that the children use a combination of verbal language, gestures and other body language, and concrete objects in their mathematical argumentation.

While this study provides insight into preschool children's mathematical arguments in the contexts of play-based activities, more research is needed to explore preschool children's mathematical arguments in different contexts using theories about and frameworks for mathematical arguments. Thus, one limitation of this study relates to the fact that the data material only consists of video recordings of play-based activities, but I belive that identifying and reconstructing mathematical arguments in other contexts is possible by using theories and analytical frameworks. In this study, my use of Nordin and Boistrup's (2018) analytical framework for identifying and reconstructing mathematical arguments may be a limitation as this framework has been developed and used for research on argumentation at the 
school level. However, by adopting a multimodal approach I believe that this study has acknowledged preschool children's broad range of argumentative resources, and thus points out that it is important to identify preschool children's argumentation. Another limitation in undertaking this type of work, with a clear multimodal focus, is that transcribing is a demanding process. I had to make certain choices with respect to which sequences to transcribe, where I chose to transcribe two partial arguments' and four full arguments' multimodality, even though claims uttered by a child were identified in 37 sequences.

Funding No funding.

\section{Declarations}

Ethical approval In order.

Informed consent Yes, in order.

Conflict of interest No conflict of interest.

Open Access This article is licensed under a Creative Commons Attribution 4.0 International License, which permits use, sharing, adaptation, distribution and reproduction in any medium or format, as long as you give appropriate credit to the original author(s) and the source, provide a link to the Creative Commons licence, and indicate if changes were made. The images or other third party material in this article are included in the article's Creative Commons licence, unless indicated otherwise in a credit line to the material. If material is not included in the article's Creative Commons licence and your intended use is not permitted by statutory regulation or exceeds the permitted use, you will need to obtain permission directly from the copyright holder. To view a copy of this licence, visit http://creativecommons.org/licen ses/by/4.0/.

\section{References}

Björklund, C. (2008). Toddlers' opportunities to learn mathematics. International Journal of Early Childhood, 40(1), 81-95.

Björklund, C. (2010). Broadening the horizon: Toddlers' strategies for learning mathematics. International Journal of Early Years Education, 18(1), 71-84.

Björklund, C., Magnusson, M., \& Palmér, H. (2018). Teachers' involvement in children's mathematizingBeyond dichotomization between play and teaching. European Early Childhood Education Research Journal, 26(4), 469-480. https://doi.org/10.1080/1350293X.2018.1487162

Breive, S. (2017). Kindergarten children's argumentation in reflection symmetry: The role of semiotic means. Paper presented at the CERME 10, Dublin, Ireland. https://hal.archives-ouvertes.fr/hal-01938941

Conner, A., Singletary, L. M., Smith, R. C., Wagner, P. A., \& Francisco, R. T. (2014). Teacher support for collective argumentation: A framework for examining how teachers support students' engagement in mathematical activities. Educational Studies in Mathematics, 86(3), 401-429. https://doi.org/10. 1007/s10649-014-9532-8

Creswell, J. W., \& Poth, C. N. (2016). Qualitative inquiry and research design: Choosing among five approaches. Sage publications.

Dovigo, F. (2016). Argumentation in preschool: A common ground for collaborative learning in early childhood. European Early Childhood Education Research Journal, 24(6), 818-840. https://doi.org/ 10.1080/1350293X.2016.1239327 
Gallistel, C. R., \& Gelman, R. (1992). Preverbal and verbal counting and computation. Cognition, 44(12), 43-74.

Johansson, M., Lange, T., Meaney, T., Riesbeck, E., \& Wernberg, A. (2014). Young children's multimodal mathematical explanations. ZDM, 46(6), 895-909. https://doi.org/10.1007/s11858-014-0614-y

Krummheuer, G. (1995). The ethnography of argumentation. The emergence of mathematical meaning: Interaction in classroom cultures (pp. 229-269). Lawrence Erlbaum Associates Inc.

Krummheuer, G. (2007). Argumentation and participation in the primary mathematics classroom: Two episodes and related theoretical abductions. The Journal of Mathematical Behavior, 26(1), 60-82.

Lee, J. S., \& Ginsburg, H. P. (2009). Early childhood teachers' misconceptions about mathematics education for young children in the United States. Australasian Journal of Early Childhood, 34(4), 37-45.

Lithner, J. (2008). A research framework for creative and imitative reasoning. Educational Studies in Mathematics, 67(3), 255-276. https://doi.org/10.1007/s10649-007-9104-2

Løkken, G. (2012). Levd observasjon: En vitenskapsteoretisk kommentar til observasjon som forskningsmetode. Cappelen Damm akademisk.

McNeill, D. (2008). Gesture and thought. University of Chicago press.

Mercier, H. (2011). Reasoning serves argumentation in children. Cognitive Development, 26(3), 177-191.

Mirza, N. M., \& Perret-Clermont, A.-N. (2009). Argumentation and education: Theoretical foundations and practices. Springer.

Mueller, M. (2009). The co-construction of arguments by middle-school students. The Journal of Mathematical Behavior, 28(2), 138-149. https://doi.org/10.1016/j.jmathb.2009.06.003

Mueller, M., Yankelewitz, D., \& Maher, C. (2012). A framework for analyzing the collaborative construction of arguments and its interplay with agency. Educational Studies in Mathematics, 80(3), 369-387. https://doi.org/10.1007/s10649-011-9354-x

Nordin, A.-K., \& Boistrup, L. B. (2018). A framework for identifying mathematical arguments as supported claims created in day-to-day classroom interactions. The Journal of Mathematical Behavior, 51,15-27. https://doi.org/10.1016/j.jmathb.2018.06.005

OECD. (2006). Starting Strong II: early childhood education and care.

Perry, B., \& Dockett, S. (1998). Play, argumentation and social constructivism. Early Child Development and Care, 140(1), 5-15. https://doi.org/10.1080/0300443981400102

Pontecervo, C., \& Sterponi, L. (2002). Learning to argue and reason through discourse in educational settings. Learning for life in the 21st century: Sociocultural perspectives on the future of education (pp. 127-140). Blackwell Publishing Ltd.

Pontecorvo, C., \& Arcidiacono, F. (2010). Development of reasoning through arguing in young children. Cultural-Historical Psychology, 4, 19-29.

Radford, L. (2002). The seen, the spoken and the written: A semiotic approach to the problem of objectification of mathematical knowledge. For the Learning of Mathematics, 22(2), 14-23.

Radford, L. (2003). Gestures, speech, and the sprouting of signs: A semiotic-cultural approach to students' types of generalization. Mathematical Thinking and Learning, 5(1), 37-70. https://doi.org/10. 1207/S15327833MTL0501_02

Radford, L. (2009). Why do gestures matter? Sensuous cognition and the palpability of mathematical meanings. Educational Studies in Mathematics, 70, 111-126. https://doi.org/10.1007/ s10649-008-9127-3

Schwarz, B. B., Hershkowitz, R., \& Prusak, N. (2010). Argumentation and mathematics. In K. Littleton \& C. Howe (Eds.), Educational dialogues: Understanding and promoting productive interaction (pp. 103-127). Taylor \& Francis.

Sfard, A. (2008). Thinking as communicating. Human development, the growth of discourses and mathematizing. Cambridge University Press.

Singer, E. (2013). Play and playfulness, basic features of early childhood education. European Early Childhood Education Research Journal, 21(2), 172-184. https://doi.org/10.1080/1350293X.2013. 789198

Stylianides, A. J. (2007). The notion of proof in the context of elementary school mathematics. Educational Studies in Mathematics, 65, 1-20.

Sumpter, L. (2016). Two frameworks for mathematical reasoning at preschool level. In T. Meaney, O. Helenius, M. L. Johansson, T. Lange, \& A. Wernberg (Eds.), Mathematics education in the early years: Results from the POEM2 Conference, 2014 (pp. 157-169). Springer.

Sumpter, L., \& Hedefalk, M. (2015). Preschool children's collective mathematical reasoning during free outdoor play. The Journal of Mathematical Behavior, 39, 1-10.

Toulmin, S. E. (2003). The uses of argument. Cambridge University Press. 
Toulmin, S., Rieke, R., \& Janik, A. (1979). An introduction to reasoning. Macmillan.

Tsamir, P., Tirosh, D., \& Levenson, E. (2009). Exploring the relationship between justification and monitoring among kindergarten children. Paper presented at the CERME, Lyon, France.

Tsamir, P., Tirosh, D., Levenson, E. S., Barkai, R., \& Tabach, M. (2017). Repeating patterns in kindergarten: Findings from children's enactments of two activities. Educational Studies in Mathematics, 96(1), 83-99. https://doi.org/10.1007/s10649-017-9762-7

van Oers, B. (1996). Are you sure? Stimulating mathematical thinking during young children's play. European Early Childhood Education Research Journal, 4, 71-87. https://doi.org/10.1080/ 13502939685207851

van Oers, B. (2010). Emergent mathematical thinking in the context of play. Educational Studies in Mathematics, 74(1), 23-37.

Vygotsky, L. S. (1978). Mind in society: The development of higher psychological processes. Harvard University Press.

Wagner, P. A., Smith, R. C., Conner, A. M., Singletary, L. M., \& Francisco, R. T. (2014). Using Toulmin's model to develop prospective secondary mathematics teachers' conceptions of collective argumentation. Mathematics Teacher Educator, 3(1), 8-26. https://doi.org/10.5951/mathteaceduc.3.1.0008

Walsh, G., Sproule, L., McGuinness, C., Trew, K., Rafferty, H., \& Sheehy, N. (2006). An appropriate curriculum for 4-5-year-old children in Northern Ireland: Comparing play-based and formal approaches. Early Years, 26(2), 201-221. https://doi.org/10.1080/09575140600760003

Yackel, E., \& Cobb, P. (1996). Sociomathematical norms, argumentation, and autonomy in mathematics. Journal for Research in Mathematics Education, 27(4), 458-477.

Zadunaisky Ehrlich, S. (2011). Argumentative discourse of kindergarten children: Features of peer talk and children-teacher talk. Journal of Research in Childhood Education, 25(3), 248-267. https://doi. org/10.1080/02568543.2011.580040

Publisher's Note Springer Nature remains neutral with regard to jurisdictional claims in published maps and institutional affiliations. 